\title{
7 THE POTENTIAL OF THE LANGUAGE ACTION PERSPECTIVE IN ETHNOGRAPHIC ANALYSIS
}

\author{
Heinz K. Klein \\ Minh Q. Huynh \\ State University of New York, Binghamton \\ U.S.A.
}

\begin{abstract}
The purpose of this paper is to explore the potential value of applying language-based methods of analyses to textual ethnographic field records (like e-mail records) in addition to thick descriptions. Even though language analysis imports many a priori assumptions, they could provide more concise summaries than thick descriptions and add value to them. The methods of conversational analysis investigated here a based on a coding scheme derived from the Wittgenstein "language use" theory of meaning combined with Habermas' social action typology. The paper presents some coding issues for discussion that we encountered along with illustrative tabulations of sample coding results. Our purpose is to illustrate the potential value of language action coding to ethnographers both during the analysis and reporting stages of research.
\end{abstract}

Keywords: Ethnographic field study, thick descriptions, language action theory, coding schemes.

\section{Introduction}

The results of ethnographic field studies are typically presented as "hick descriptions" in the form of narratives or "stories." The disadvantage of thick descriptions is that they tend to be rather verbose and make it difficult to form a global picture of the social phenomena being researched. The general purpose of the research underlying this paper 
is to investigate the possibility of using some form of language-action analysis on the same textual ethnographic field records (such as tape recording transcripts or e-mail records) as are used to formulate thick descriptions. Such language-based analysis could yield more concise summaries than thick descriptions and thereby add value to them. We do not imply here that language action analysis can entirely replace thick descriptions, but at least they could help to identify "salient" or prominent characteristics in the ethnographic data. Hence, language action based forms of analysis would be secondary to thick descriptions, but they could play an important exploratory and summarizing role in ethnographic research. Our approach is rooted in the "semantic content analysis" in which coding is based on meaning rather than word counts. On the other hand, it is not a grounded theory approach because the researchers enter into the examination of the texts with an initial set of predetermined content variables extracted from our framework (Truex and Ngwenyama 1998, p. 452).

Specifically, we shall explore in this paper whether a descriptive analysis of the field records with a language action theory based coding scheme could shed additional light on the social phenomena to be studied. Examples of what we mean by social phenomena are the collaborative processes that occur in a group project for a college level course. Although group work in college is not the same as collaborative work in industry because of the "artificial" nature of the instructor centered classroom setting, student work groups should qualify as a convenient testing ground for new research methodologies. This paper will report some preliminary results of testing the application of the language action theory to obtain a global view of the nature of the social interaction in such collaborative student group settings. To avoid possible misinterpretation of the data analysis presented later in this paper, it is important to keep in mind that our purpose here is not to test any hypothesis or make any assertions on group processes. Rather, our intention merely is to explore the feasibility of drawing on the language action theory for the development of a coding scheme and illustrate its use for coding and interpreting a given "text." We seek feedback on the feasibility and potential pitfalls of our proposed methods.

The remainder of the paper is organized as follows. Section 2 explains the theoretical background for developing language action coding schemes and the setting in which the ethnographic "data," i.e., field records from participant observation and online group interaction transcripts, were collected. Section 3 presents some coding examples and reports the difficulties encountered in applying Habermas' action types to ethnographic "data." Section 4 analyzes tentative results from coding samples and section 5 summarizes our conclusions about the potential value added of using language action theory based coding schemes with ethnographic field studies.

\section{Theoretical Background and Research Setting}

Our long-term objective is to design a research methodology that will help us to understand the dynamics of group processes from an insider's perspective. As such an understanding is always incomplete, we intend to focus on such aspects as may be suggestive for designing technical systems that are compatible with social group processes. We presume that the understanding should come first and information technology design second. 
We start with the common sense assumption that at the micro level all group interactions can be understood in terms of elementary acts or sequences of such acts. In some cases, these action sequences may be as simple as asking questions, accessing information, manipulating information, etc. In other cases, they may be quite complex, such as solving problems through sophisticated strategies, mitigating group conflict or building group cohesiveness and forming consensus through compromise and mutually accepted critique. In general, all these processes involve a series of transactions and transformations that lead to the creation, processing, distribution, use, control and management of data, information, and knowledge. The most obvious manifestation of the knowledge creation is in the ordinary speech and writings that are used as the medium of communication, including special symbols such as figures or models to support ordinary speech.

In accordance with the literature on speech act theory, language should be a form of human action. In order to capture the full meaning of language, we may need to resort to identifying the human actions that provide the ultimate rationale or purpose of one or several speech acts. Hence, we may need larger units of analysis than individual sentences or speech acts. Possible larger units are the social action types as Habermas (1984) proposed them in his "Theory of Communicative Action": instrumental, strategic, communicative, expressive, normatively regulated and discursive actions. Because these action types have already been widely discussed in the IS literature (e.g., Hirschheim, Klein, Lyytinen 1995 and 1996 or Cecez-Kecmanovic 1994), we will take them for granted here. However, a key point to keep in mind is that the action types are not easily identified at the micro level. Therefore, by themselves, they are not a good coding scheme. Nevertheless, the orientations underlying these action types can be very helpful to interpret the meaning of what people say or do and therefore helpful for constructing a more sophisticated coding scheme.

For the research site selected in this study, the following three orientations suggested themselves as the most important. The first is the instrumental (or meansends) orientation to accomplish a set goal. The second is the communicative orientation, which prevails when people engage in communications to achieve agreement or shared understandings. The third orientation is called discursive and can be observed when conversation partners seek clarifications and reasons for claims made in the course of ongoing interactions. Hence, discursive action challenges what is being said, but seeks to restore agreement by giving good reasons abstaining from using force or other forms of power (e.g., court litigation). If the orientation is to get one's way (success) by means of power, this turns the communication partner into an opponent and the underlying orientation is instrumental (to achieve success in terms of one's own predefined objectives). This action type is called strategic, because it is directed against human opponents (or other organisms that can be expected to also act strategically) as opposed to inanimate objects, which don't have a mind of their own.

Speech acts are supposed to be the most basic units of ordinary speech, which at the vocal level consists of a series of utterances. Consistent with prior literature (i.e., Dietz and Widdershoven 1991) there are only four classes of speech acts, namely assertions, instructions, commitments (like promises), or declarations (like giving notice). As in prior research (cf. Klein and Truex 1996), we found it very difficult to classify all text that makes up ordinary group interactions in everyday life into one of those four speech acts. Hence we resorted to a typology that is richer and more flexible. Its original version 
was proposed by P. B. Andersen (1991). Based on Wittgenstein's analysis of language use, Andersen called the basic units in his typology "language games." These language games have different connotations from those in "mind games" or "games people play." The language games that seemed most appropriate for our research site are defined in Figure 1.

By analyzing what the group members tried to accomplish with their words in the group meetings, we sought to identify a set of language games to capture the universe of discourse of student group meetings, i.e., all that students typically say in study groups. We did this in two steps. First, a stable core set of language games could be transferred directly from prior work, i.e., Andersen (1991) and Klein and Truex (1996). As in prior research, the language games could easily be organized into a few fundamental types. Most likely these can be observed in many different contexts. Second, we identified additional language games that were not encountered in previous research. They are specific to the universe of discourse in the student group meetings studied here. Examples are the language games aimed at organizing the group or those aimed at accomplishing something specific such as tasks needed in writing a college report, the language games aimed at maintaining the group or smoothing social interactions or those aimed at mastering or controlling the technology. In general, the language games within each major type need to be adjusted to the specific research site context under consideration. Klein and Truex discuss the details of adjusting language games in developing a coding scheme.

The research setting for which the language games in Figure 1 were constructed consisted of carefully selected graduate-level courses with semester projects, because we did not have access to participant observation of an industry project group. The data used in this paper came from the "Leadership in Organizations" course. It is an MBA course offered to School of Management students who pursue the leadership certificate program. Although the field study at this specific site lasted only 15 weeks, its data interpretation benefitted from the background knowledge of a larger research project that involved several research sites and extended over a period of 18 months.

The major objective of this leadership course is for students to experience and gain insights into the emergence and development of leadership. There are several reasons why we believed that complex group interactions are likely to occur in the student project groups for this course and why this course would be a suitable testing ground for developing our research methodology. First, a unique feature of the teaching strategy in this course is the explicit role of the instructor as a facilitator rather than a knowledge disseminator. Students are expected to assume the ownership not only for their learning but also for that of others. Another important element of collaborative learning in this class is the emphasis on knowledge sharing. The course is carefully structured with tasks requiring students to share their work with each other.

Secondly, the course requirement of relevance to our research is the emphasis placed on many forms of student participation. These include in-class discussion, engagement in online chats, publishing work on the web and reviewing others' work. In addition, students are required to write a personal journal and an integrating essay to reflect their learning in the course. Finally, there is a group project that synthesizes the course materials covered into a full package of documentation and presentation.

A third attractive feature that makes this leadership course useful for research on group processes is the integration of user-friendly group support software into the course 
design. One of such groupware applications is TeamWave, which offers students a wide range of tools to use online. With TeamWave, students can work together at any time and in any place, e.g., chatting and brainstorming in a group, making a group decision or voting, arranging and organizing meetings, keeping track of and sharing the group's files, and so on. We took full advantage of the automatic transcript or recording facilities of TeamWave to obtain the best set of records possible.

The data presented in this paper was extracted from one of the case discussions in TeamWave. In this leadership class, the online case discussion was conducted regularly once a week outside of class time. At a scheduled time, students would log on TeamWave either locally from the school's public computing facility or remotely from their home or work place. The main objective of these online sessions was to discuss the reading materials or certain selective topics that the instructor assigned. In these online sessions, two specific tools of TeamWave-Brainstormer and Chat-were used to facilitate students' analysis of the assigned cases. In the Chat window, students had the ability to type their comments or to have a textual conference with each other. After typing in text and hitting the <Return $>$ key, their statements would be displayed in the chat screen along with their log-in name. Everyone in the session would be able to see the statements from their screen. This is how users communicate to each other interactively online. Similar to the Chat, the Brainstormer also serves as a place for students to contribute their comments but in an anonymous mode because the students' names are not automatically displayed.

In principle, we proposed that understanding group learning in this leadership course involves analyzing the sequences of language actions. These language actions are performed by the actors under the influence of other components; namely, technology, pedagogical context, and group processes. It is hypothesized that all communicative transactions that occur in this context are driven by one of the three basic orientations that are at the core of Habermas' definitions social action types. The three orientations are instrumental, communicative, and discursive. They are associated with the group members' motivations and intentions when acting as group members. We assumed that one of the three orientations is dominant during one or more language games for each group member. This assumption led us to propose to combine the language games with Habermas' action types into the single coding scheme of Figure 2. In this coding scheme the orientations are coded as part of the five action types shown as column headers in Figure 2, i.e., the instrumental orientation is associated with instrumental and strategic actions while the communicative orientation is associated with normatively regulated and communicative actions.

\section{Coding Issues}

\subsection{The Procedures Used in the Coding}

From the online case discussions in the "Leadership in Organizations" course that we shall refer to as the $\mathrm{H} 5$ course, we selected two transcripts for the analysis in this paper. As mentioned earlier, these case discussions were conducted weekly in TeamWave and 


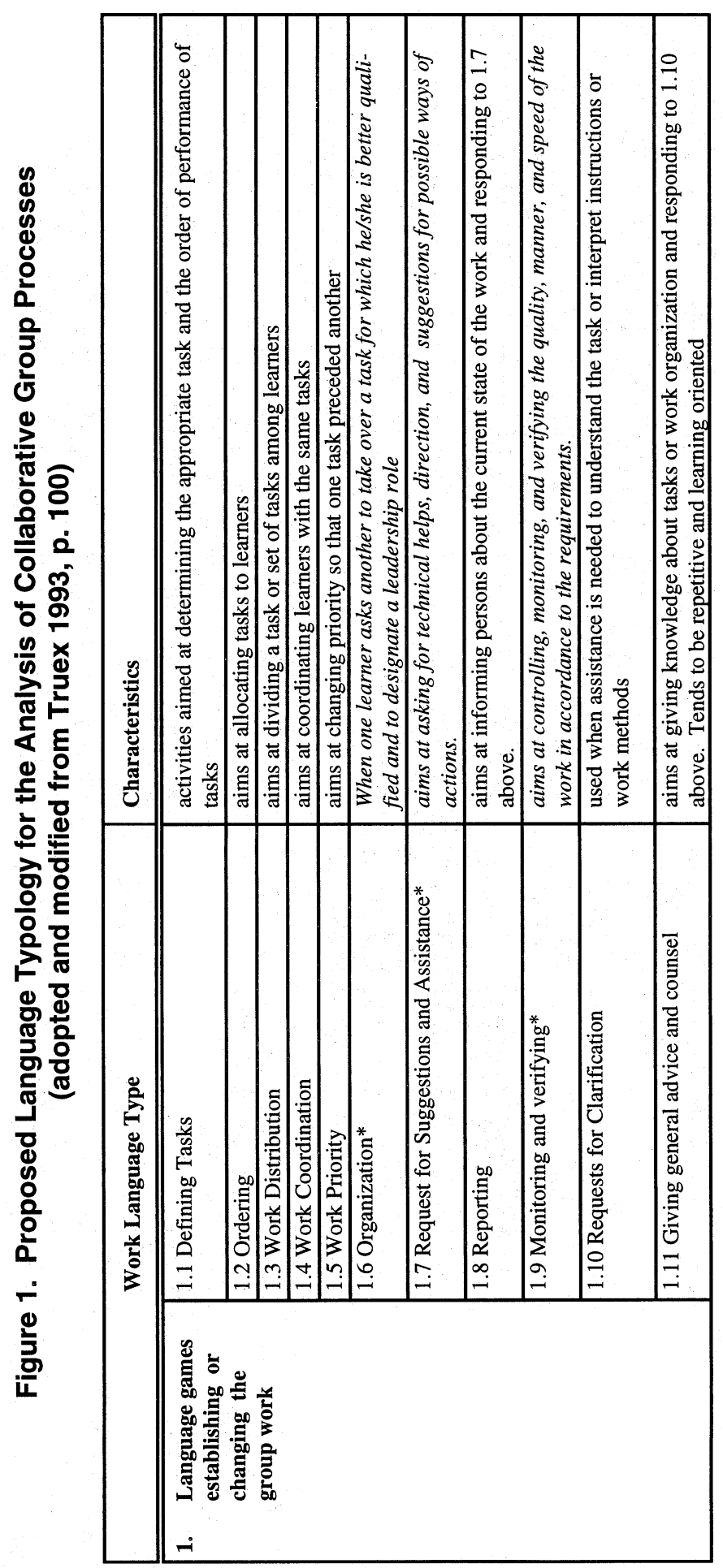




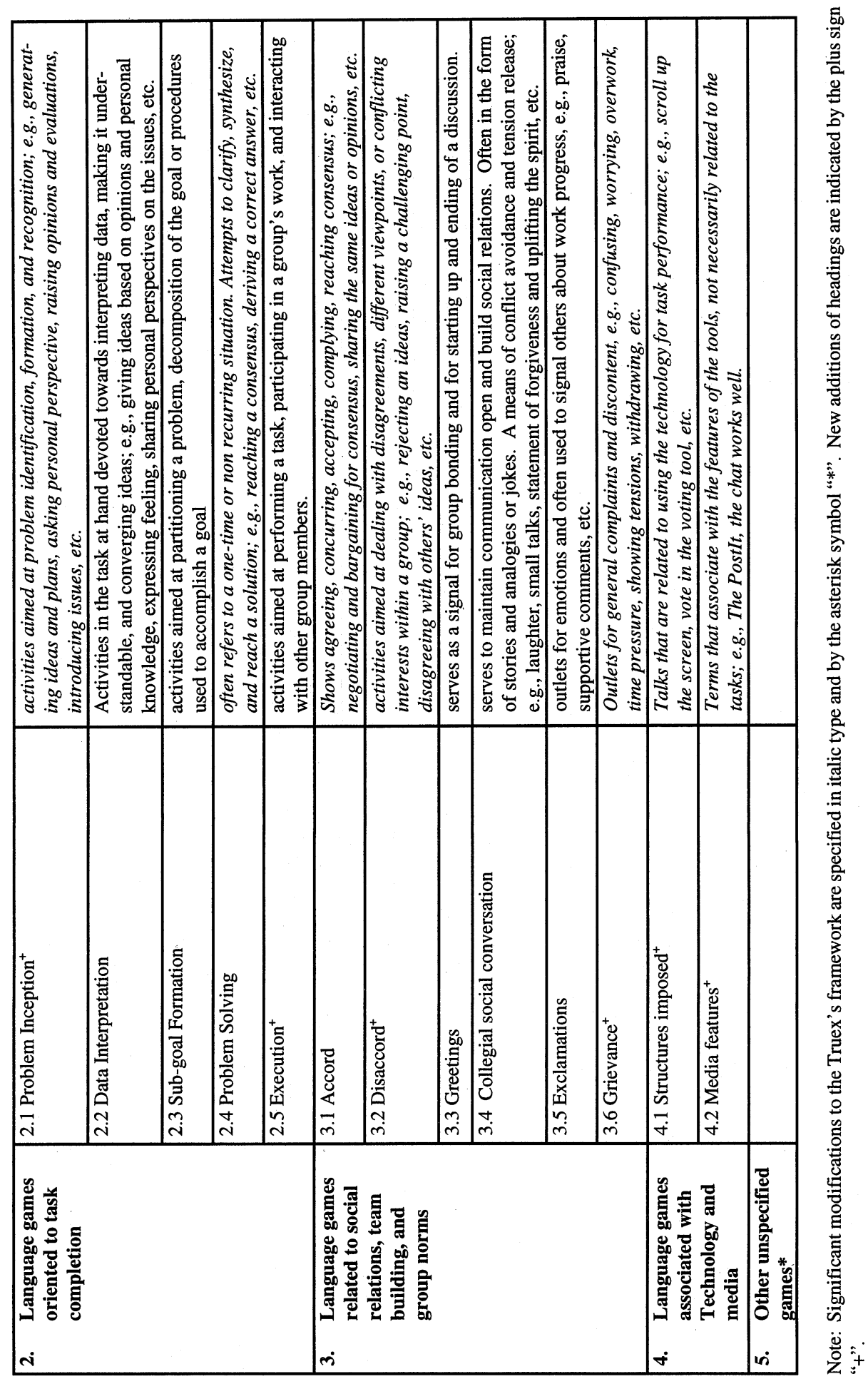




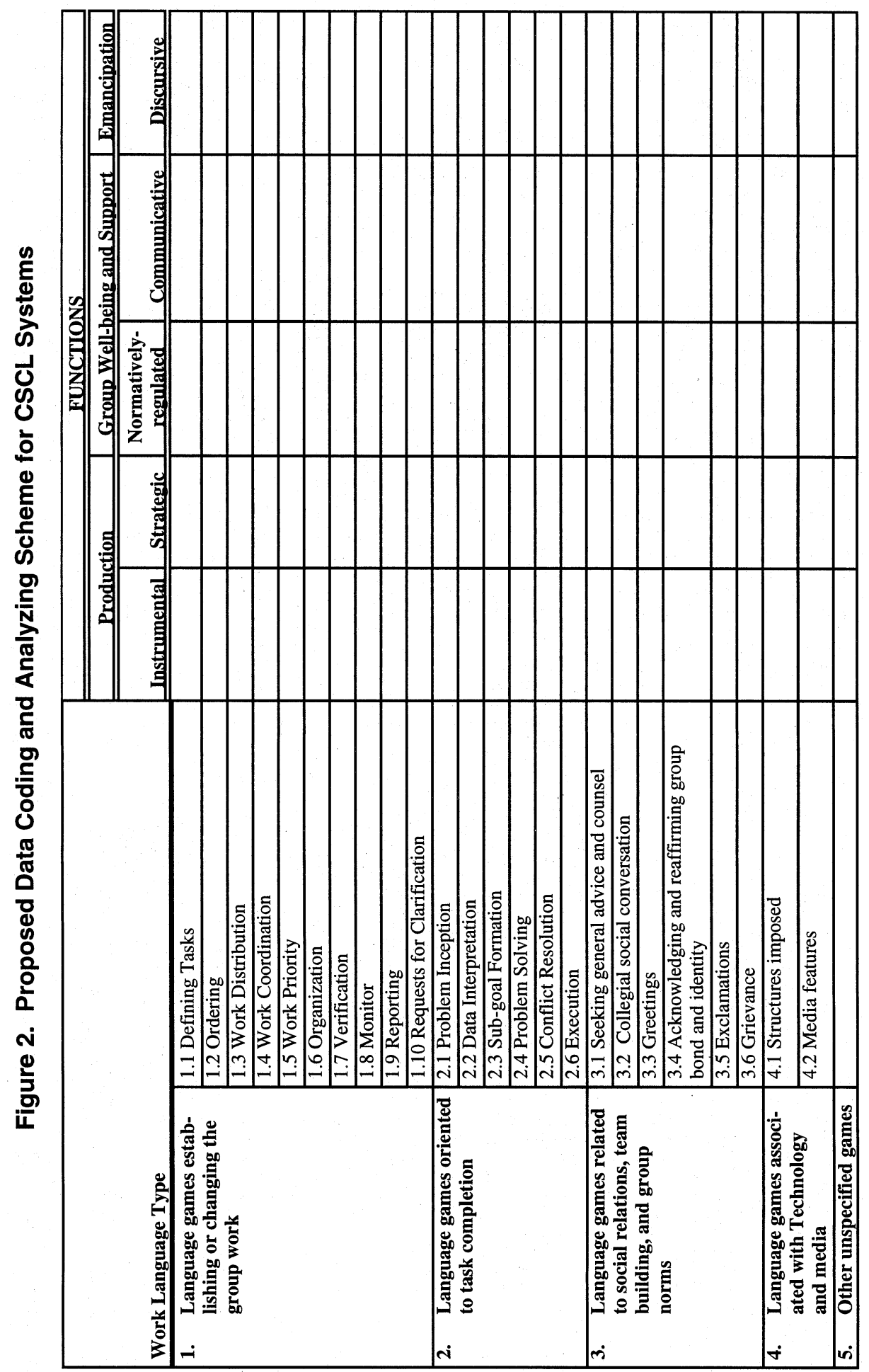


lasted about an hour. The average number of discussants was about 9-10 students. Because the discussions were text-based, all the communicative transactions were readily captured in transcripts as records. For simplicity, we limited our analysis on a sample of two sessions because our interest here is to explore the feasibility of the proposed coding scheme rather than to make any claims in group learning. In reading the transcripts from these meetings, we found sufficient evidence that they provide valuable insights into how a group works together on a complex task in a virtual environment over an extended period of time. However, we chose to present our analysis as illustrative examples of what other ideas can be gleaned from language action coding.

The first step in the coding was to convert the transcripts into text documents. Next, we imported these text documents into a qualitative data analysis program called ATLAS/ti. From the ATLAS/ti application, we began reviewing the transcripts. As we read and interpreted the statements in the transcripts (often with discussions among the authors), we assigned a code to a meaningful portion of text. One of the authors did the entire coding of the transcripts. Since we did not have outsiders available to serve as cross-coders and inter-coders, the other author had to be involved in the coding process. $\mathrm{He}$ checked the major sections of the coded transcripts from the first author. When incongruences arose, we met and resolved the differences ourselves. The codes were drawn from the predefined language types and Habermas' action types in the proposed coding scheme of Figure 2. The unit of analysis was based on one or more statements that expressed a complete thought or action; however, what constituted a complete thought or action was quite subjective. After coding all the transcripts, one of the authors ran queries from ATLAS/ti to obtain the frequency counts on each of the codes, i.e., selecting all the statements coded as "Act-Communicative". The results of these summary statistics will be presented in section 4 . In this section we wish to focus on the difficulties that we encountered with resolving ambiguities as we applied the coding scheme.

\subsection{Coding Difficulties}

The sample transcript in Figure 3 is an excerpt from one online case discussion session in the H5 course (Transcript H50226, p. 2). Through TeamWave, learners could log in from different locations and participate in a real-time discussion. The Brainstormer tool in TeamWave was used to facilitate group interactions in this session. It supported a free format interaction that allowed learners to contribute their comments at any time. Another noticeable feature of this excerpt was its anonymity. Through the Brainstormer, learners could contribute either their comments or ideas without revealing their identity. As a result, it is not possible to trace the origin of these statements and associate them to a specific participant in these sample transcripts.

In this excerpt, the focus of the discussion was on the issue of leadership impact and the role of leaders in organizational change. In the contribution prior to line 68 , one student "gave advice" "that there is a cycle of change that we need to pay attention to when effecting system-wide change." He then listed Nadler's five change activities: "(1) recognizing the change imperative, (2) developing a shared direction, (3) implementing change, (4) consolidating change, and (5) sustaining change." The language game of this passage was coded as "giving explanation" and the action type as 


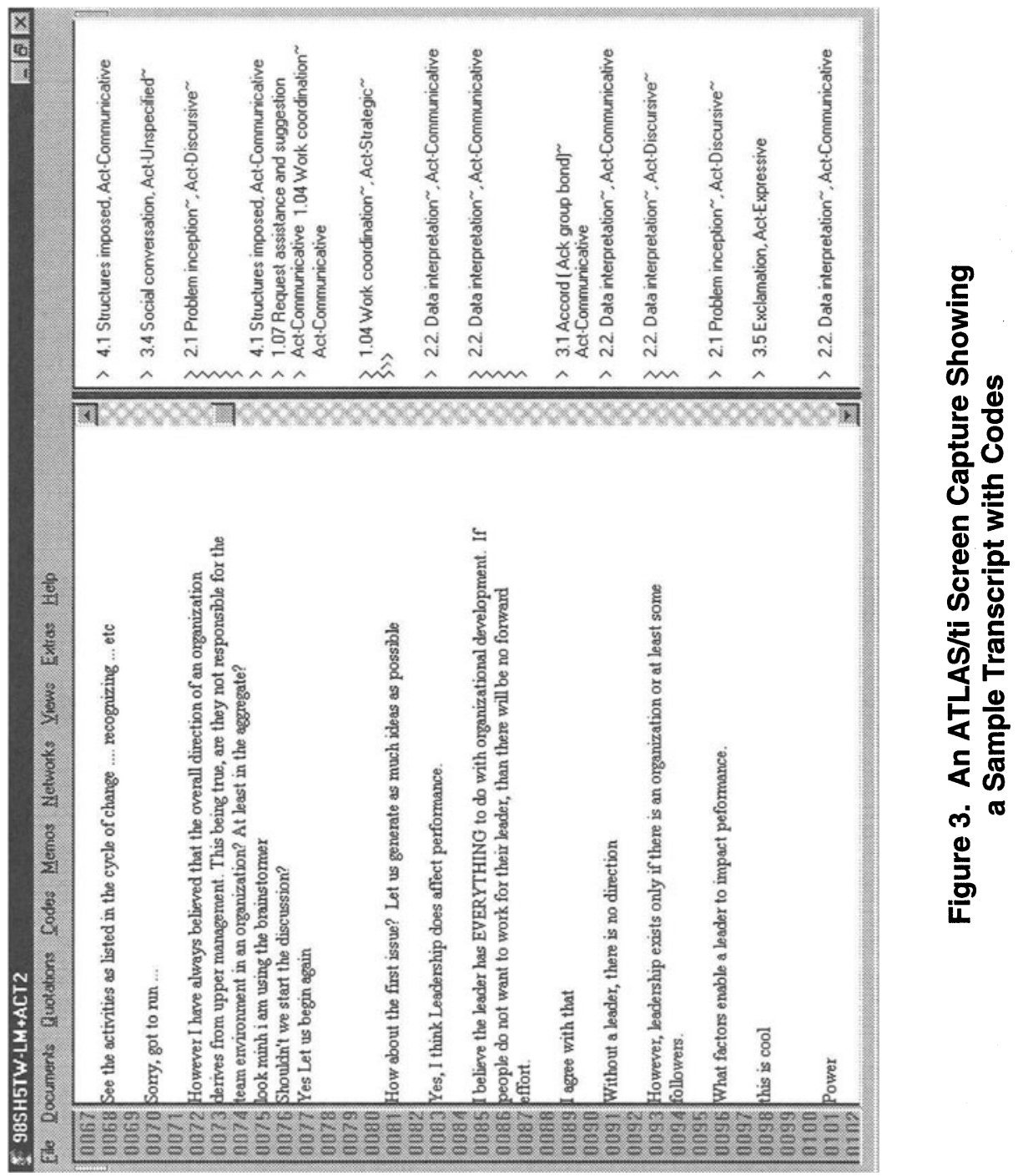


"instrumental." After this, another student raised the following question "I wonder what the substantive and symbolic 'acts' would be with regard to this cycle of change. With the term 'acts,' do you mean the specific tasks of a team and leader or the overall goals?" This question was coded as "problem inception." The action type was coded as "communicative" and not "discursive" because the question did not really challenge any claims or assumptions from the preceding statements.

At this point, we will step the reader through a portion of the transcript and the coding shown in Figure 3. The result is shown in Figure 4. For brevity, we singled out only those statements from Figure 3 for discussion in Figure 4 that are ambiguous and problematic for the language action coding. From Figure 4, it will become apparent that the language game coding is relatively straightforward whereas the action type coding is much more ambiguous and subjective. Consequently, the reliability in the action type coding might turn out to be low.

The key point that we try to convey here is that the coding of action types relies on subjective judgments and contextual interpretation. As we shall describe in the analysis of coding summary, the difficulty is not the lack of the authors' experience or knowledge, but it is inherent in the whole approach of language action coding at its current state. There are simply no predefined rules to determine the proper unit of analysis. Should the social action types be analyzed at the sentence, paragraph, or issue-related level? In the next section, we will present our language action analysis based on each utterance. Although it is difficult to justify each action type coding, the result of cross coding both the language action types and the language games shows some interesting insights of collaborative group processes that might be hidden from other methods of analyses, i.e., thick descriptions, dictionary-based content analysis.

\section{Analysis of Coding Summaries}

As is evident from the prior discussion, we are faced with the following paradox. Whereas the coding of language games is fairly straightforward after some training and experience, it is insufficient to capture the full meaning of speech. Only if coding of language games is combined with action type coding can we capture some of the subtleties of the ongoing group interactions. However, coding for action types is full of ambiguities rendering the coding less reliable. This is true even for researchers who are very familiar with Habermas' Theory of Communicative Action. What seems to be surfacing here is some sort of linguistic Heisenberg principle: The more meaning we try to capture (i.e., the cross coding with language games type and action type), the less precise become the measurements (i.e., the ambiguities illustrated in Figure 4). The richness of cross coding can be elaborated in more detail with Figure 5.

Figure 5 was obtained by projecting the language games across different social actions of Habermas. The purpose of this cross tabulation is to explore the values and intentions underlying the language games. Our fundamental conjecture is that Habermas' five action types (namely instrumental, strategic, normatively regulated, communicative, and discursive action) represent most of significant social actions occurring in group processes. This study suggests that the values and intentions underlying different language games can be clarified substantially by cross-coding them with Habermas' action types. The reason for this is that the language games categories 


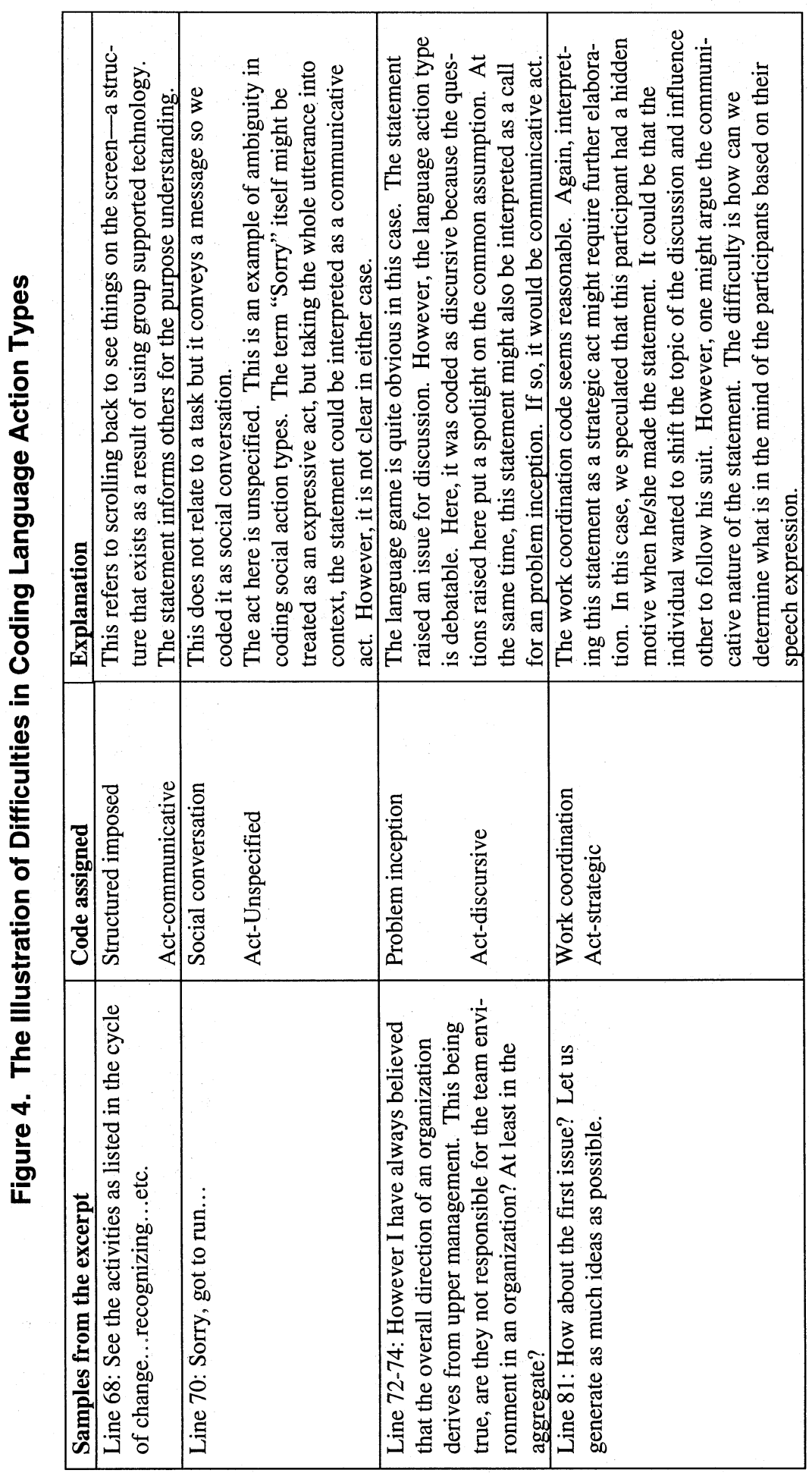


Result of coding Habermas action types in $\mathrm{H} 5$ case discussions. Note: X-axis: types of language move, Zaxis: action types, and $\mathrm{Y}$-axis: percentage of statements

口 COM DIS DINSD NOR ESTR

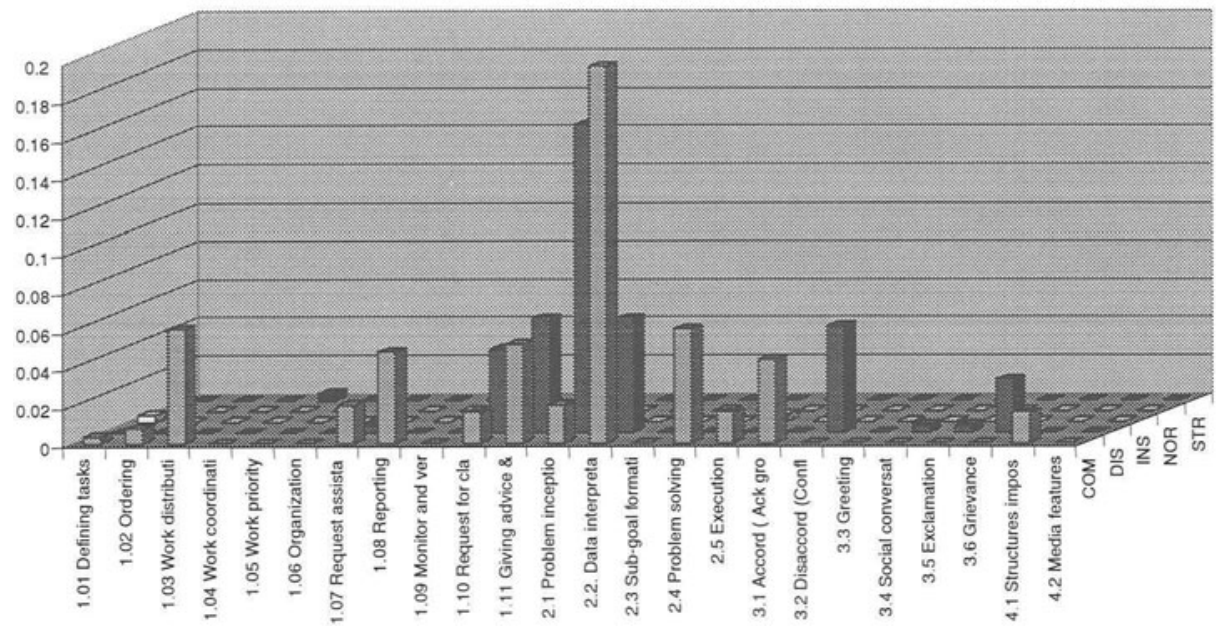

Figure 5. Result of Coding Language Games Cross Habermas' Action Types in the Case Discussions of the H5 Course

do not capture the underlying motives or intentions, which they serve. These motives are captured by the Habermas' action types. Hence language game coding alone is chronically insufficient whenever the same language game can serve different action types.

This observation is very evident from analyzing the following four language games in Figure 5: 1.10 Request for clarification, 1.11 Giving advice, 2.1 Problem inception, and 2.2 Data interpretation. These language games account about half of the conversation, hence are very critical communications. To clarify the point of chronic insufficiency of language game coding, let us single out 1.11 , the "Giving advice" game. Clearly the meaning of "giving advice" is very different depending on whether the underlying orientation is to challenge some prior points (merely couched politely in terms of advice) or simply to offer some additional pieces of information to round out the picture that might have been overlooked by the listener. In the former case, the action type is discursive in the latter communicative. The giving advice game is almost evenly split among these two very different action types.

Similar observations can be made for the other three language game types. As shown in Figure 5, most of the problem inception language games are discursive, i.e., the interactions were aimed at challenging group members' opinions or positions. A similar pattern holds for the rRequests for data clarifications" (1.10). They also appear to be mostly discursive. The reverse is true for data interpretation language games: only one quarter is discursive and about three-quarters are communicative. 


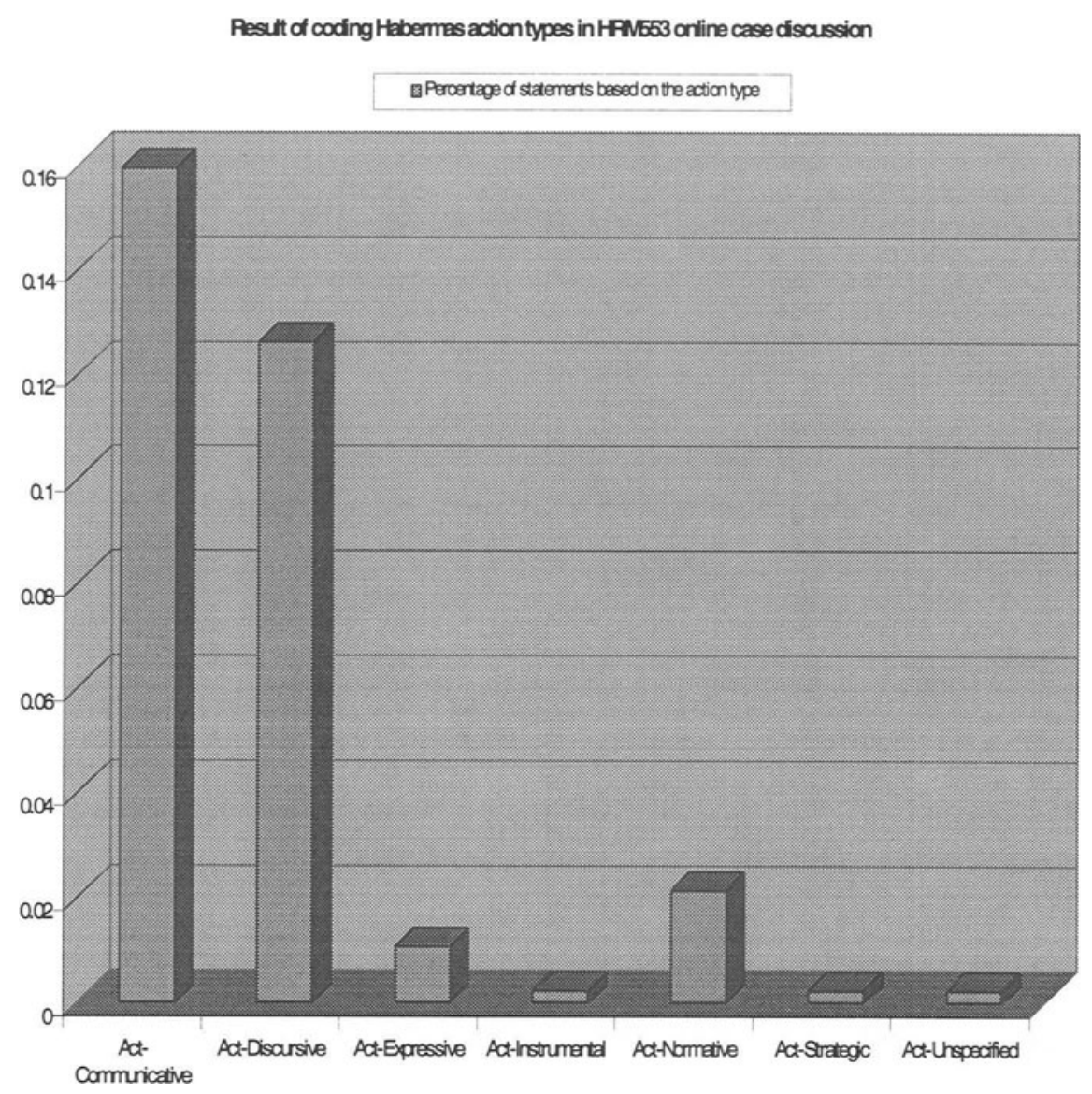
Figure 6. The Result of Coding Habermas' Action Types in a Sample of H5 Online Case Discussion

In principle, we expect the distribution will vary depending on the social context in which the transcripts are generated, i.e., a consultation with the tax auditor would produce a distribution that is very different from that of a psychotherapy session. Given a very large number of texts and utterances, the shape of the utterance frequencies might not be necessarily stable because they are subject to the influence of various factors including group climate, task goal, group spirit, group composition, and so on.

There are a few more observations that can be made with the help of the coding summary in Figure 5. For instance, on the whole, the communicative action appears to be dominant (cf. Figure 6). This orientation indicates the values and intentions that the group members placed on achieving consensus and shared sense-making. Group 
members viewed themselves as partners engaging in negotiation and interpretation for shared understandings. This is further illustrated in the Figure 6.

Figure 6 shows the total number of statements in percentage with respect to different types of Habermas' social action types in all four online sessions of case discussion in the H5 course. From this figure, one interpretation of the group's interaction is that the group showed a high level of collaboration. It is evident in the large number of communicative actions that are oriented toward negotiation, coordination, and reaching consensus. In contrast, there are a smaller number of discursive statements that reflect disagreement, conflict, and argumentation. In hostile or confrontational groups, one would expect that strategic and discursive actions are much more frequent than were observed in our sample data. Hence the analysis method introduced could also provide of measure of the group climate on the cooperative vs. confrontational dimension.

In summary, adding the dimension of Habermas' action types reveals a deeper level of meaning in the group interactions. It shows us different orientations of the communication in which the group members engage. It allows us to take a closer look at the inside of group processes where values and intentions manifest themselves. It sheds light on the transformation where sense-making, shared meaning, and consensus building take place.

\section{Conclusions and Further Research Implications}

The paper reflects on the potential contribution from developing and using a coding scheme that is based on the language action theory. Based on an earlier study and its adaptation to a new setting, we concluded that such a coding scheme provides ethnographic researchers a valuable tool to examine group interactions at a deeper and more global level than the traditional thick description. Of course there are at least two challenges to this claim. The first is that the coding scheme rests on a number of a priori assumptions, which are imported by the researcher from "the outside" and therefore may not have any grounding in the field records. There is an obvious counter argument to this. Klein and Myers (1999) found that many ethnographic studies exhibit a heavy a priori theoretical bias even if they solely rely on thick descriptions because they tend to use external theories for interpreting the field records and for selecting the contents and format of their descriptions. Hence, no matter which research method is used, some theoretical bias is inevitable.

The second challenge that a language action coding scheme faces is the difficulty with achieving sufficiently reliable coding results. In other words, the coding methods need to improve the inter-raters' consistency and agreement. This is important for giving evidence for the plausibility and cogency of results. If coders trained in the same methods, but with otherwise different backgrounds, are presented with the same text, the tabulation of the results should be similar at least to the extent that they agree on the interpretation of the original thick descriptions. If the results vary with the coders, then they appear more or less arbitrary, because the reader cannot follow the logic of the coding in detail whereas thick descriptions are supposed to be sufficiently detailed so that the reader can form his own judgements.

However, even if coding consistency is not achievable, we made the case that the proposed language action coding scheme still is a valuable idea generation tool during 
the research process (the context of discovery). This is so because the coding scheme tabulation and interpretation are trustworthy only if supported by the thick descriptions. The latter are the warrant that the global characteristics captured in the tabulation of coding results depict qualities that are in some sense "true." True in this sense merely means that any claims made in the course of reporting results can be substantiated with the thick description accounts of the people's "lived experience," who perceived the phenomena about which academic claims are made. What is at stake here is the relationship between two socially constructed realities: those of the people whose lives are being studied and those of the researchers who try to understand them in their writings. We assume that the former is prior and hence any academic claims must be anchored to the lived experiences of the people whose experiences the academics try to understand.

\section{References}

Andersen, P. B. "A Semiotic Approach to Construction and Assessment of Computer Systems," in Information Systems Research: Contemporary Approaches and Emergent Traditions, H-E. Nissen, H. K. Klein and R. Hirschheim (eds.). Amsterdam: Elsevier (North Holland), 1991, pp. 465-514.

Cecez-Kecmanovic, D. "Business Process Redesign as the Reconstruction of a Communicative Space," in Business Process Re-Engineering: Information Systems Opportunities and Challenges, B. C. Glasson, I. T. Hawryszkiewycz, B. A. Underwood and R. A. Weber (eds.). Amsterdam: Elsevier Science (North-Holland), 1994.

Dietz, J. L. G., and Widdershoven, G. A. M. "Speech Acts or Communicative Action?" in Proceedings of the Second European Conference on Computer Supported Cooperative Work: $E C S C W^{\prime}$, L. Bannon, M. Robinson and K. Schmidt (eds.). Dordrecht, The Netherlands: Kluwer, 1991, pp. 235-248.

Habermas, J. The Theory of Communicative Action, Volume One, tr. T. McCarty. Boston: Beacon Press, 1984.

Hirschheim, R.; Klein, H. K.; and Lyytinen, K. Conceptual and Philosophical Foundations of ISD. Cambridge, England: Cambridge University Press, 1995.

Hirschheim, R.; Klein, H. K.; and Lyytinen, K. "Exploring the Intellectual Structures of Information Systems Development: A Social Action Theoretic Analysis," Accounting, Management, \& Information Technology (6:1/2), 1996, pp. 1-64.

Klein, H. K., and Truex, D. P. "Discourse Analysis: An Approach to the Analysis of Organizational Emergence," in The Semiotics of the Work Place, B. Holmqvist, P. B. Andersen, H. K. Klein and R. Posner (eds.). Berlin: W. DeGruyter, 1996, pp. 227-268.

Klein, H. K., and Myers, M. D. "A Set of Principles for Conducting and Evaluating Interpretive Field Studies in Information Systems," MIS Quarterly (23:1), March 1999, pp. 67-93.

Truex, D. P. Information Systems Development in the Emergent Organization, Unpublished Doctoral Dissertation, Binghamton University, New York, 1993.

Truex, D. P., and Ngwenyama, O. K. "Unpacking the Ideology of Postindustrial Team-Based Management: Self-governing Teams as Structures of Control of IT Workers," in Proceedings of the Work, Difference and Social Change: Two Decades after Braverman's Labor and Monopoly Capital Conference, R. Baldoz, P. Godgrey, C. Jansen, C. Koeber, P. Kraft (eds.). Binghamton, New York, May 8-10, 1998, pp. 447-461. 


\section{About the Authors}

Heinz K. Klein earned his Ph.D. at the University of Munich and was awarded an honorary doctorate by the University of Oulu, Finland, for his academic contributions to the IS faculty's research program. He is currently Associate Professor of Information Systems at the State University of New York, Binghamton. Well known for his contributions to the philosophy of IS research, foundations of IS theory and methodologies of information systems development, he has written articles on rationality concepts in ISD, the emancipatory ideal in ISD, principles of interpretive field research, alternative approaches to information systems development and their intellectual underpinnings. His articles have been published in the best journals in the field including Communications of the ACM, MIS Quarterly, Information Systems Research, Information Systems Journal, Information Technology and People, Decision Sciences, and others. He has also co-authored or edited several research monographs and conference proceedings in IS. He serves on the editorial boards of the Information Systems Journal, Information, Technology and People and the Wiley Series in Information Systems. He can be reached by e-mail at hkklein@ binghamton.edu.

Minh Q. Huynh earned his Ph.D. in Information Systems and an MBA in the School of Management, State University of New York, Binghamton. He also holds a BA in Physics from Franklin and Marshall College, and BS in Computer Science from the University of Maryland. Prior to his academic career, Minh worked for in computing for four years with the U.S. federal government. His dissertation, A Critical Study of Computer-Supported Collaborative Learning, was completed in 1999. It combined analysis of ethnographic thick descriptions with focus group interviews and language analysis coding. His other research interests include application of social theory in IS research, the advancement of interpretive research and language action analysis methods. So far, he has published in the conference proceedings of the International Federation of Information Processing, International Resources Management Association, and North Eastern Decision Sciences Institute. He can be reached at br00328@binghamton.edu. 